\title{
Perioperative Management of Patients with Rheumatic Diseases
}

\author{
Manal Alotaibi, Khaled Albazli, Lina Bissar, \\ and Hani Almoallim
}

\subsection{Introduction}

The aim of this chapter is to present a simple approach to the assessment of patients with different rheumatologic diseases, especially rheumatoid arthritis (RA), before undergoing orthopedic surgery. Perioperative assessment confirms an early diagnosis of the patient's medical condition and comorbidities, overall health, and the assessment of the risk factors associated with the proposed interventions. Perioperative assessment allows for proper postoperative man-

M. Alotaibi

Northwestern University Feinberg School of Medicine, Chicago, IL, USA

Internal Medicine Department, College of Medicine, Umm Al-Qura University, Makkah, Saudi Arabia e-mail: manal.alotaibi@northwestern.edu

\section{K. Albazli}

Department of Medicine, Faculty of Medicine in Al-Qunfudhah, Umm Al-Qura University, Makkah, Saudi Arabia

The George Washington University School of Medicine and Health Sciences, Washington, DC, USA

L. Bissar $(\square)$

Department of Medicine, King Faisal Specialist

Hospital and Research Center (General

Organization), Jeddah, Saudi Arabia

e-mail: lbissar@kfshrc.edu.sa

H. Almoallim

College of Medicine, Umm Al-Qura University,

Makkah, Saudi Arabia

e-mail: hmmoallim@uqu.edu.sa agement of complications. It can also aid in the management of high-risk drugs used by rheumatologic patients such as disease-modifying antirheumatic drugs (DMARD), antiplatelets, and corticosteroids. The assessment also supports postoperative plans and patient education [1-3].

\subsubsection{Objectives}

1. To present a comprehensive preoperative medical evaluation for patients with rheumatologic disorders before undergoing orthopedic surgery.

2. To clarify the assessment of specific clinical issues in patients with RA and systemic lupus erythematosus (SLE).

3. To present the perioperative management of medications for patients with rheumatologic disorders before undergoing orthopedic surgery.

4. To clarify how to follow-up and educate the patient postoperatively.

\subsection{The Preoperative Medical Evaluation}

\subsubsection{History Taking}

Detailed information should be obtained. There are several components of the history that should 
be outlined. These include the patient's age, duration of rheumatologic disorder, current functional level, specific joint involvement with arthritis, any extra-articular manifestations of the disease, current medications including DMARDs and previous use of steroids, previous complications associated with surgery, and any comorbidities like hypertension and/or diabetes mellitus.

\subsubsection{Physical Examination}

Obviously, for any rheumatic disease patients, there should be specific focus on the musculoskeletal system during the physical examination. This should include posture, location and pattern of joint involvement, gait, and range of motion (ROM) of the examined joints. Furthermore, underlying disorder must be identified. The skin should also be assessed for any manifestations suggestive of an underlying rheumatologic diseases that may impact skin integrity.

\subsubsection{Investigations}

The following tests may be considered along with routine tests:

- A complete blood count for an examination of possible drug related hematologic side effects. This may include anemia due to gastric or duodenal irritation, leukopenia, and/or pancytopenia from massive bone marrow suppression. This is essential in situations where significant blood loss is expected, such as total hip replacements.

- A complete renal profile, liver enzymes, and liver function tests to screen for DMARDs side effects.

- A urinalysis and urine culture should be obtained. It is important to rule out urinary tract infections in patients undergoing total joint arthroplasty $[4,5]$.

- A 12-lead electrocardiogram (ECG) is necessary as a baseline cardiovascular evaluation for patients undergoing surgeries. ECG is recommended in men over the age 40 and women over 50 having major surgery. This is essential even in the absence of history or physical exam findings.

- Chest X-ray is necessary as a baseline for pulmonary evaluation. It is indicated for patients over the age 50 undergoing major joint or spine surgery. This is even in the absence of symptoms and/or signs suggestive of active pulmonary disease $[6,27]$.

\subsubsection{Assessment of Specific Clinical Problems in Patients with RA}

\subsubsection{Cardiovascular}

Special focus should be made to risk stratify RA patients for coronary artery disease. Many contributing factors including accelerated atherosclerosis put RA patients at high risk for cardiac morbidity and mortality. RA patients presenting for orthopedic surgery for any kind of procedure and/or intervention should receive careful preoperative cardiac risk stratification. There are several measures to be taken. Dipyridamole thallium scintigraphy (DTS) conducted preoperatively is found to be most useful to stratify selected nonvascular surgery patients at intermediate or high risk by clinical assessment [6$9,28]$.

\subsubsection{Pulmonary}

Multiple pulmonary complications including fibrosis, bronchiolitis, and pleuritis can have significant impact on RA patients. Serial pulmonary function test (PFT) among patients with RA is recommended. This can help in early detection of defected ventilation. [10]

\subsubsection{Cricoarytenoid Arthritis}

This is a common involvement in RA patients. It places concerns of complicated intubation or obstructed airway after surgery. Most patients are asymptomatic, but despite that they may present with symptoms such as hoarseness, sore throat, and/or difficult inspiration. Therefore, it is extremely essential to avoid intraoperative musculoskeletal trauma in patients with RA by applying generous padding during joint positioning and by avoiding sudden movements of the neck and torso [11, 23-26]. 
Table 18.1 Perioperative management of antirheumatic drugs

\begin{tabular}{|c|c|}
\hline Antirheumatic drug & Comments \\
\hline $\begin{array}{l}\text { Methotrexate } \\
\text { (MTX) }\end{array}$ & $\begin{array}{l}\text { - There is no increased risk of infection or other postoperative complications in patients } \\
\text { with RA who continued MTX. } \\
\text { - Continue the current dose of methotrexate for patients undergoing elective total hip } \\
\text { arthroplasty (THA) or total knee arthroplasty (TKA). } \\
\text { - Withheld the week before and the week after surgery if there are additional concerns } \\
\text { regarding the perioperative safety of MTX such as renal insufficiency or if a more } \\
\text { complex surgical intervention is required. } \\
\text { - MTX should be reinstated as soon as the patient is stable postoperatively. } \\
\text { - MTX treatment should be discontinued until full recovery if prolonged surgery or } \\
\text { artificial respiration is anticipated or in case of pulmonary complications, to reduce the } \\
\text { risk of pneumonia [30,31]. }\end{array}$ \\
\hline TNF blockers & $\begin{array}{l}\text { - It is recommend stopping TNF blockers use } 1 \text { to } 4 \text { weeks before surgery, proportional to } \\
\text { the drugs half-lives. } \\
\text { - Withhold TNF blockers and other biologic agents prior to surgery in patients undergoing } \\
\text { elective THA or TKA, and schedule the surgery at the end of the dosing cycle. } \\
\text { - Treatment may be restarted at minimum } 14 \text { days postoperatively if there is no evidence of } \\
\text { infection and once wound healing is satisfactory [32]. }\end{array}$ \\
\hline Tocilizumab & $\begin{array}{l}\text { - Infection rates attributed to tocilizumab are comparable to those associated with other } \\
\text { biologic DMARDs. } \\
\text { - Discontinuing tocilizumab } 11 \text { to } 13 \text { days before surgery, based on the drug half-life, is a } \\
\text { safe approach to perioperative therapy }[31,33] \text {. }\end{array}$ \\
\hline $\begin{array}{l}\text { SLE specific } \\
\text { medications: } \\
\text { Mycophenolate } \\
\text { mofetil } \\
\text { Azathioprine } \\
\text { Cyclosporine } \\
\text { Tacrolimus }\end{array}$ & $\begin{array}{l}\text { - Withhold their current doses } 1 \text { week prior to surgery in all patients with stable SLE } \\
\text { undergoing THA or TKA. } \\
\text { - Continue their current doses through the surgical period in all patients with severe SLE } \\
\text { undergoing THA or TKA. }\end{array}$ \\
\hline Rituximab & $\begin{array}{l}\text { - Rituximab has been shown to be safe in patients with prior recurrent bacterial infections. } \\
\text { - Compared with TNF blockers, rituximab is associated with a lower risk for bacterial } \\
\text { infections, which are the primary concern in perioperative management, although the } \\
\text { presence of low immunoglobulin levels in a small proportion of patients raises the } \\
\text { infection risk. } \\
\text { - Elective surgery can be arranged in the } 7 \text { th month from the last given dose [31]. }\end{array}$ \\
\hline Abatacept & $\begin{array}{l}\text { - The risk of infection in patients treated with abatacept is not significantly increased over } \\
\text { baseline non-biologic-treated RA patients. } \\
\text { - Abatacept is administered either as a monthly infusion or a weekly subcutaneous } \\
\text { injection, and conservative timing of surgery should be at the end of the dose cycle [31]. }\end{array}$ \\
\hline Steroid & $\begin{array}{l}\text { - In general, limiting minimal doses of steroids preoperatively should be considered to } \\
\text { prevent impairment of wound healing and surgical site infections. } \\
\text { - Chronic use of steroid also increases the potential risk of subversive consequences of an } \\
\text { inadequate adrenal response [31]. }\end{array}$ \\
\hline
\end{tabular}

\subsection{Perioperative Drug Management}

\subsubsection{Perioperative Management if Antirheumatic Drugs [12-16]}

\subsubsection{Perioperative Management of Other Systemic Medications} $[12-14,16,17]$

(See Table 18.2)

(See Table 18.1) 


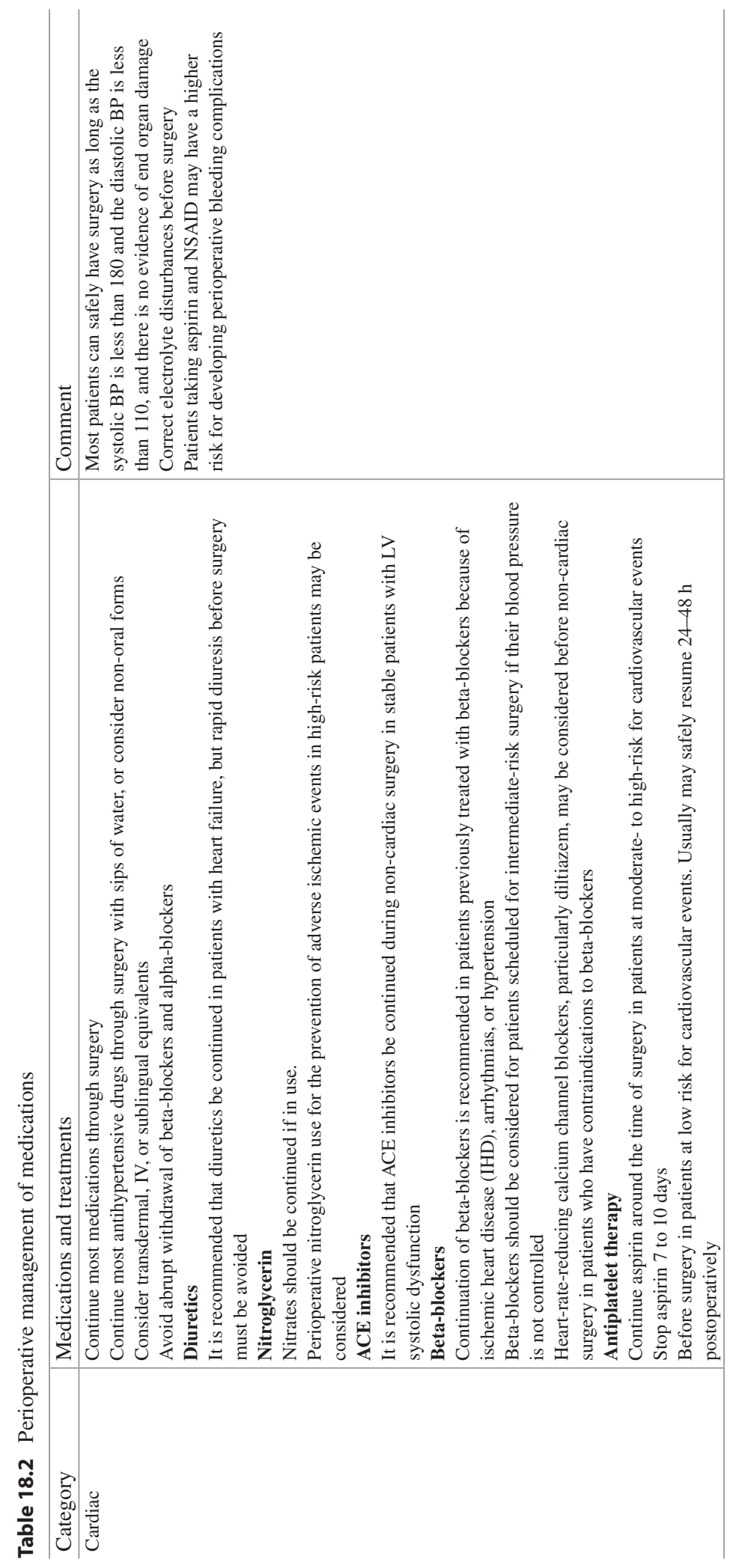




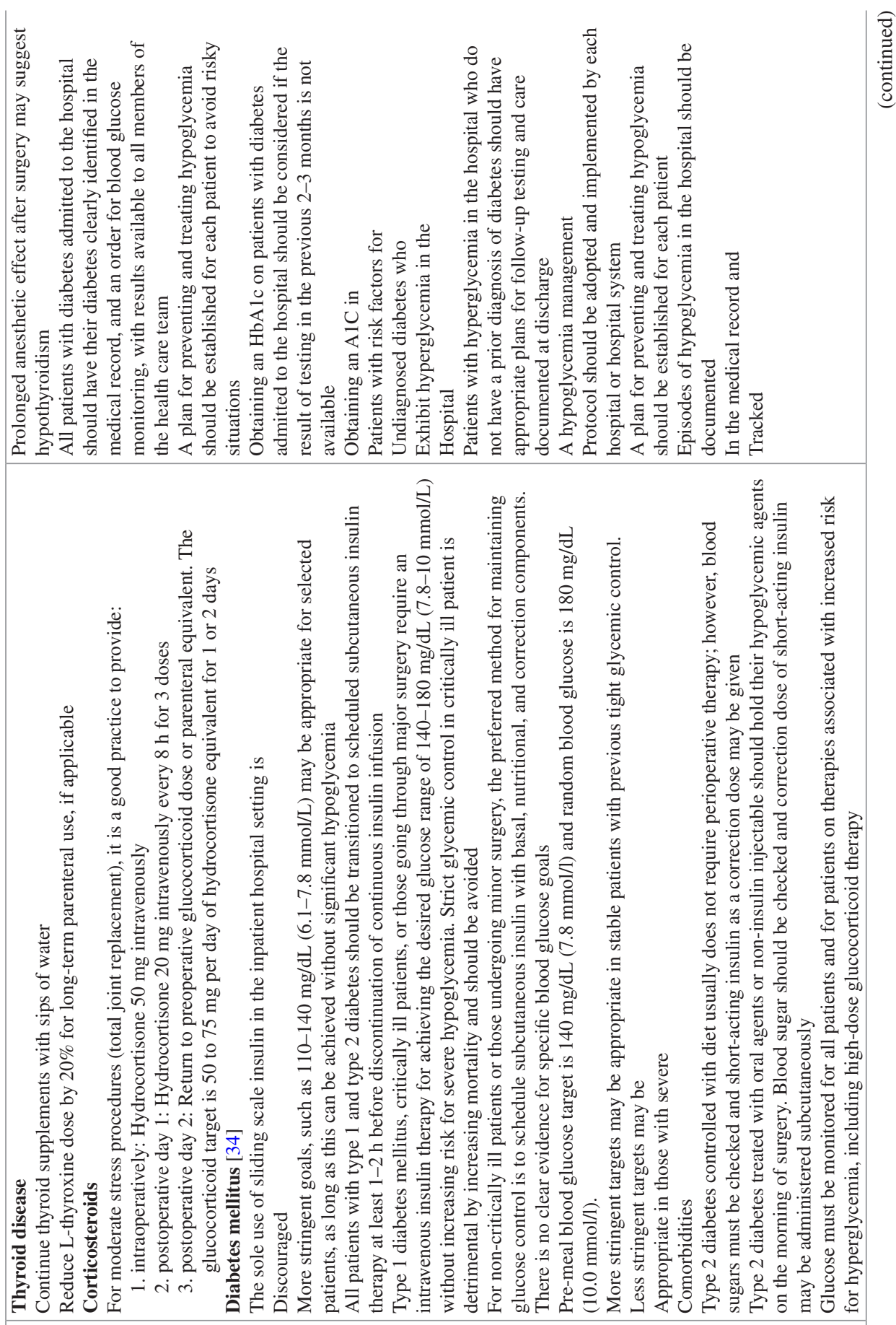




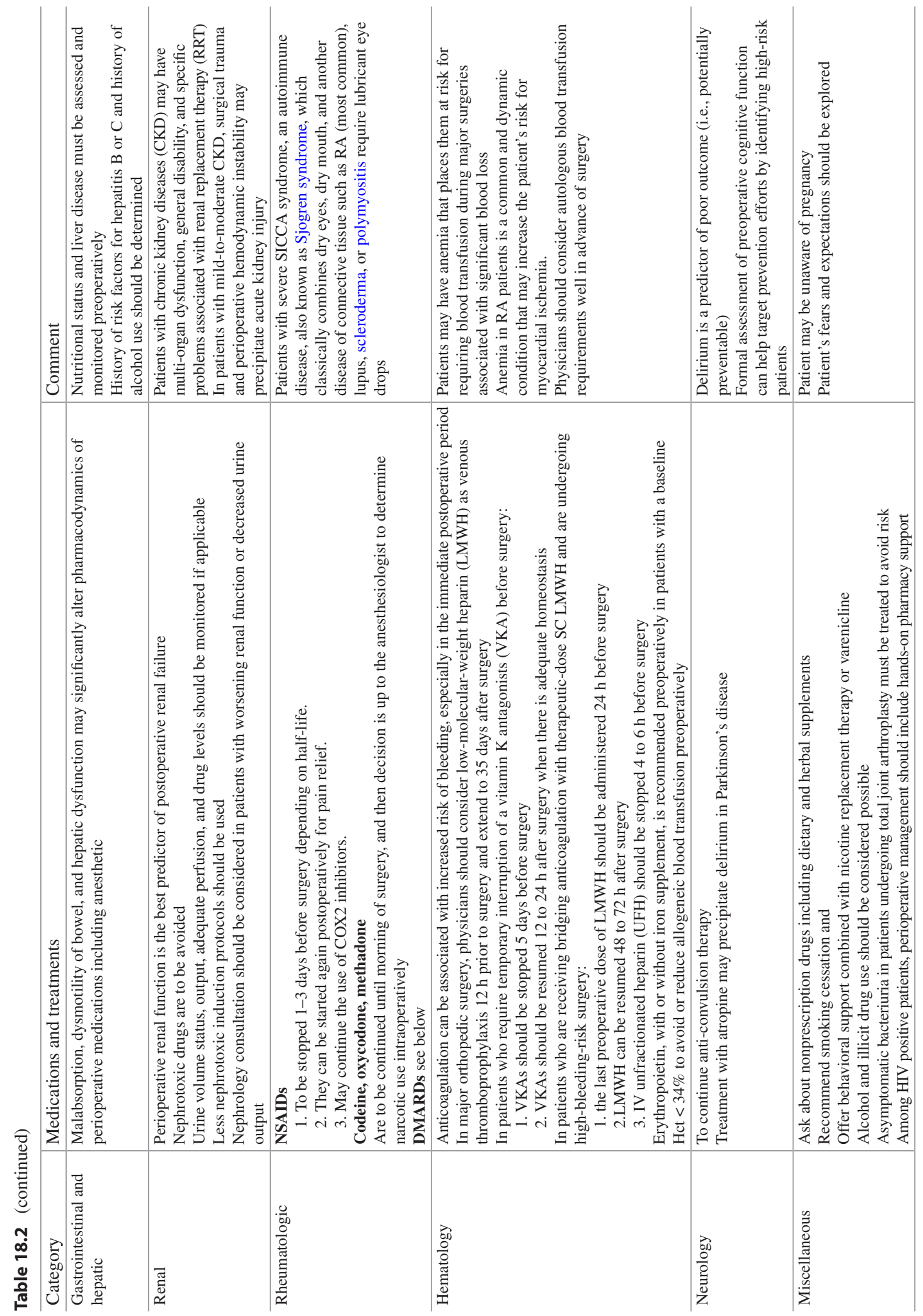




\subsubsection{DVT Prophylaxis}

- Meta-analysis showed that extended-duration prophylaxis against deep vein thrombosis (DVT) with low-molecular-weight heparin (LMWH) or unfractionated heparin (UFH) in patients with major hip or knee replacement surgery can reduce the risk of symptomatic venous thromboembolism significantly [18].

- There are many options for the prevention of venous thromboembolism in patients undergoing elective hip or knee arthroplasty and who are not at increased risk beyond that of the surgery itself for venous thromboembolism or bleeding. Prophylaxis should be started after surgery (specific timing given separately for each drug) and continued for 28-35 days for hip patients and 10-14 days for knee patients: dabigatran, fondaparinux, LMWH, rivaroxaban, and UFH (for patients with renal failure) are all options [18, 19, 35].

- It has to be considered that the benefit here is associated with increased risk of minor bleeding but with no excess major bleeding [18].

- In patients undergoing hip fracture surgery (HFS), it is recommended to use one of the following rather than no antithrombotic prophylaxis for a minimum of 10 to 14 days: LMWH, fondaparinux, LDUH, adjusted-dose VKA, or aspirin.

- There are specific considerations for patients undergoing major orthopedic surgery, total hip arthroplasty (THA), total knee arthroplasty (TKA), hip fracture surgery (HFS), and receiving $\mathrm{LMWH}$ as thromboprophylaxis; it is recommended to start either $12 \mathrm{~h}$ or more preoperatively or $12 \mathrm{~h}$ or more postoperatively, rather than within $4 \mathrm{~h}$ or less preoperatively or $4 \mathrm{~h}$ or less postoperatively $[19,36]$.

- It has to be noted that in patients undergoing THA or TKA, irrespective of the concomitant use of an intermittent pneumatic compression device (IPCD) or length of treatment, it is suggested to use LMWH in preference to the other agents recommended as alternatives: fondaparinux, apixaban, dabigatran, rivaroxaban, low-dose UFH, adjusted-dose vitamin $\mathrm{K}$ antagonist (VKA), or aspirin.

\subsubsection{Prophylactic Antibiotics}

$[20,29]$

- Prophylactic antibiotics are needed for RA patients who will be undergoing long procedures especially patients with TKA, joint replacement, and prosthetic joints. This is to prevent surgical site infections.

- Obviously, antibiotics must be administered to patients undergoing surgery in an infected area with a high bacteremia risk.

- Cefazolin or cefuroxime antibiotics are the antibiotic of choice and should be given 30 to $60 \mathrm{~min}$ before skin incision.

- In case of a confirmed B-lactam allergy, vancomycin may be used. It should be started within $2 \mathrm{~h}$ prior to incision.

- The dose of antibiotic varies according to patient's weight; for patients $>80 \mathrm{~kg}$, the doses of cefazolin should be doubled.

- It has to be noted that additional intraoperative doses of antibiotic might be needed. It should be given for prolonged procedures and if there is significant blood loss during the procedure.

- Prevention of wound infection is essential. This can be prevented after surgical repair of closed fractures by a single dose of cephalosporin.

- Prophylactic antibiotics should be stopped within $24 \mathrm{~h}$ of the end of surgery.

\subsection{Assessment of Specific Clinical Problems in Patients with SLE}

Specific perioperative concerns must be considered for patients with SLE undergoing orthopedic surgery. This should include assessing risk factors for worse outcomes including smoking or use of oral contraceptive pills (OCP), adequate blood pressure (BP), and lipid control. It has to be noted that SLE patients undergoing both nonelective and elective hip and knee surgery have a high mortality and morbidity rate compared to RA patients [21].

It is also necessary to assess medication management around the operation time. SLE patients 
have multiple organ involvement. This should be assessed as well including hematologic abnormalities, renal disease, and immune dysfunction, and thromboembolic disease. Moreover, a careful balance should be addressed in the risk assessment in patients with antiphospholipid antibody syndrome (APS). The aim is to evaluate these patients preoperatively to decrease the risk of major bleeding and the risk of a thromboembolic event.

\subsection{Postoperative Follow-Up}

There has to be a thorough postoperative risk assessment for the following patients:

- Carful follow-up for patients with RA and SLE assessing the risk of prosthetic joint infections, DVT, and pulmonary embolism. These patients have greater risk for the development of these complications postoperatively.

- Hospitalized patients with autoimmune disease have a high risk of postoperative venous thrombosis. These patients can be offered a regional anesthesia, as it reduces the postoperative DVT significantly.

- Patients with gout should be assessed for the risk of flare of gout postoperatively.

- There are special precautions for patients with Raynaud's phenomenon. Hypothermia must be avoided postoperatively and pressure ulcers must also be prevented [22].

\subsection{Patient Education}

To assure patients' safety, it is recommended to inform the patient of the following:

- Patients should be aware about the expected duration of movement limitations and options for pain control. This is immediately after the surgery and in the following weeks to months.
- They should also be aware about the importance of a comprehensive physical activity program following surgery.

- Each patient should be aware of the pain control plan. The associated fluctuation of pain with different medication withdrawal or institution must be explained.

- More details should be delivered to patients according to their needs, issues like possible drug-drug and/or drug-food interactions of new medication regimens. The classical and common examples are the potential risk of anticoagulant drugs and foods affecting potency of warfarin. Patients should be aware about any follow-up instructions including monitoring of laboratory investigations.

- Obviously, patients should be aware about the importance of early immobilization [22].

\subsection{Physical Activity and Rehabilitation}

Patients should undertake physical therapy since physical activities are essential for patients with rheumatologic disease. The major benefits are to prevent disabilities, restore function, and relieve pain. These activities should be evaluated preoperatively to verify consistency with treatment goals. These are greatly augmented by prescribed therapeutic exercises and functional activities. Special precautions should be given for patients with active inflammatory joint or soft tissue diseases. The therapeutic exercises should be balanced with essential rest periods for a successful treatment. The aim is usually dedicated at preserving or increasing functional level, decreasing pain and joint inflammation, and increasing range of motion and strength [22].

Figure 18.1 illustrates a summary of perioperative management of patients with rheumatic diseases. 


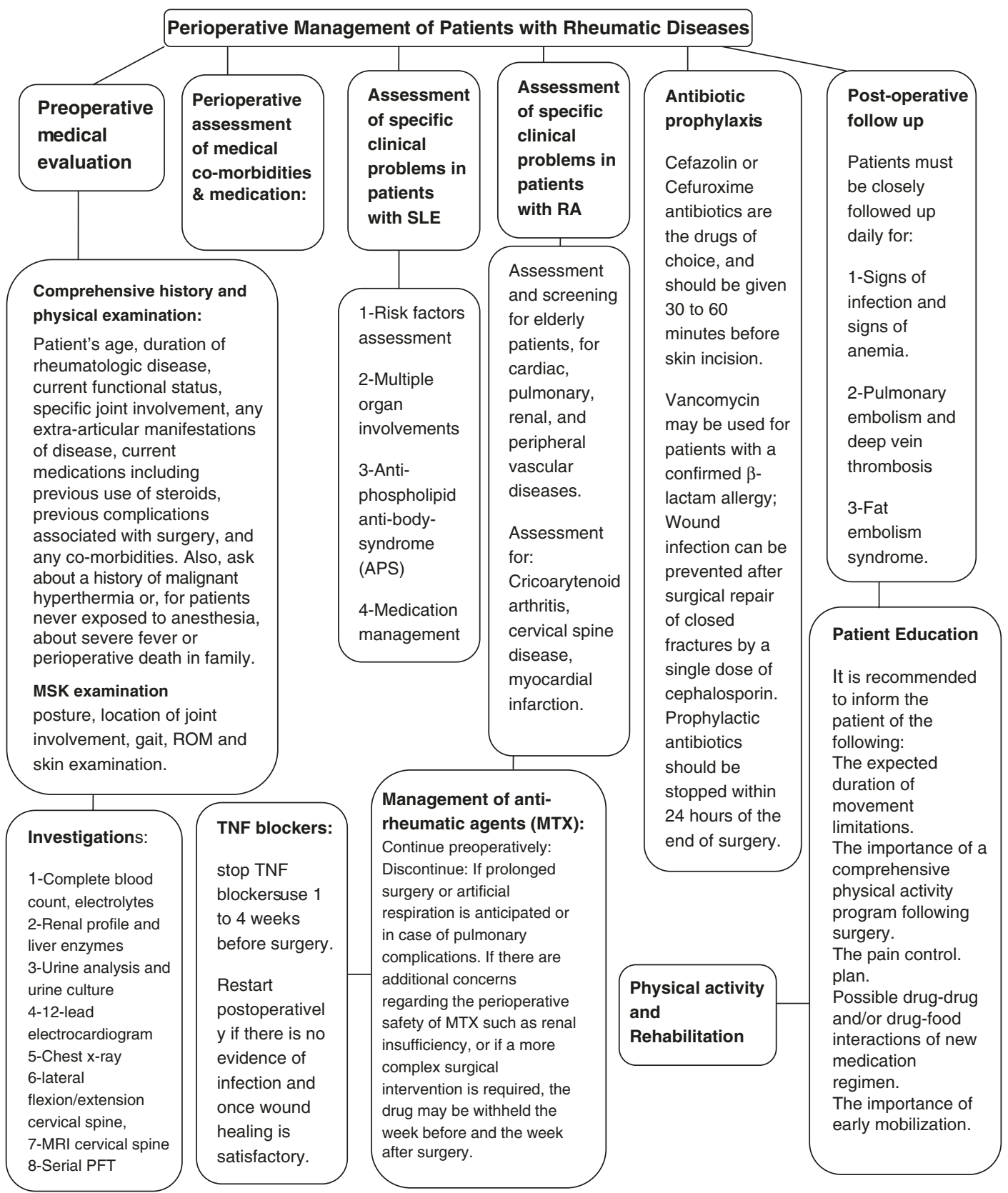

Fig. 18.1 Summary of the Perioprative Mangment of Patients with Rheumatic Diseases

\section{References}

1. Paget SA, editor. Hospital for special surgery manual of rheumatology and outpatient orthopedic disorders: diagnosis and therapy: Lippincott Williams \& Wilkins; 2006.
2. Walker J. Care of patients undergoing joint replacement. Nurs Older People. 2012;24(1):14-20.

3. MacKenzie CR. Perioperative Medical Care of Rheumatic Disease Patients Having Orthopaedic Surgery. 2004; http://www.hss.edu/professionalconditions_perioperative-medicalcare-of-rheumaticdisease-patients-having-orthopaedic-surgery.asp. 
4. Koulouvaris P, Sculco P, Finerty E, Sculco T, Sharrock NE. Relationship between perioperative urinary tract infection and deep infection after joint arthroplasty. Clin Orthop Relat Res. 2009;467(7):1859-67.

5. Sousa R, et al. Is asymptomatic bacteriuria a risk factor for prosthetic joint infection? Clin Infect Dis. 2014:ciu235.

6. Silvestri L, Maffessanti M, Gregori D, Berlot G, Gullo A. Usefulness of routine pre-operative chest radiography for anaesthetic management: a prospective multicentre pilot study. Eur J Anaesthesiol. 1999;16(11):749-60.

7. Kannel WB, Abbott RD. Incidence and prognosis of unrecognized myocardial infarction. An update on the Framingham study. N Engl J Med. 1984;311(18):1144-7.

8. Lee TH, Marcantonio ER, Mangione CM, et al. Derivation and prospective validation of a simple index for prediction of cardiac risk of major noncardiac surgery. Circulation. 1999;100(10):1043-9.

9. Fleisher LA, et al. 2014 ACC/AHA guideline on perioperative cardiovascular evaluation and management of patients undergoing noncardiac surgery. Circulation. 2014:CIR-0000000000000106.

10. Wong C. The medicine consult handbook. 4th ed; 2011.

11. Jackson MB, et al. The perioperative medicine 1 consult handbook: Springer International Publishing Switzerland; 2015. https://doi. org/10.1007/978-3-319-09366-6_1.

12. Lee MA, Mason LW, Dodds AL. The perioperative use of disease modifying and biologic therapies in patients with rheumatoid arthritis undergoing elective orthopedic surgery. Orthopedics. 2010;33(4):257-62.

13. Grennan DM, Gray J, Loudon J, Fear S. Methotrexate and early postoperative complications in patients with rheumatoid arthritis undergoing elective orthopaedic surgery. Ann Rheum Dis. 2001;60(3):214-7.

14. Harle P, Straub RH, Fleck M. Perioperative management of immunosuppression in rheumatic diseases what to do? Rheumatol Int. 2010;30(8):999-1004.

15. del Olmo BH L, Galindo-Izquierdo M, Tébar D, Balsa A, Carmona L. Perioperative management of disease modifying antirheumatic drugs: Recommendations based on a meta-analysis pubmed Revista Española de Cirugía Ortopédica y Traumatología (English Edition). Rev Esp Cir Ortop Traumatol. 2012;56(5):393-412.

16. Goodman SM, Springer B, Guyatt G, et al. 2017 American College of Rheumatology/American Association of hip and Knee Surgeons Guideline for the perioperative Management of Antirheumatic Medication in patients with rheumatic diseases undergoing elective Total hip or Total knee arthroplasty. Arthritis Care Res. 69:1111-24. https://doi. org/10.1002/acr.23274.

17. Carmona L, Galindo M. Perioperative management of immunosuppression. Oxford Textbook of Rheumatology. Oxford, UK: Oxford University Press, 201310. Oxford Medicine Online. 20161027.
Date Accessed 26 Feb. 2017 <http://oxfordmedicine. com/view/10.1093/med/9780199642489.001.0001/ med-9780199642489-chapter-93>.

18. Eikelboom JW, Quinlan DJ, Douketis JD. Extendedduration prophylaxis against venous thromboembolism after total hip or knee replacement: a meta-analysis of the randomised trials. Lancet. 2001;358(9275):9-15.

19. Sun Y, Chen D, Xu Z, Shi D, Dai J, Qin J, et al. Deep venous thrombosis after knee arthroscopy: a systematic review and meta-analysis. Arthroscopy. 2014 Mar;30(3):406-12.

20. American Academy of Orthopaedic Surgeons. Recommendations for the use of intravenous antibiotic prophylaxis in primary total joint arthroplasty. 2004. (Revised 2014).

21. Domsic RT, Lingala B, Krishnan E. Systemic lupus erythematosus, rheumatoid arthritis, and postarthroplasty mortality: a cross-sectional analysis from the nationwide inpatient sample. J Rheumatol. 2010;37(7):1467-72.

22. Cohn SL. Preoperative evaluation for noncardiac surgery. Ann Intern Med. 2016;165(11):ITC81-96.

23. Crosby ET, Lui A. The adult cervical spine: implications for airway management. Can J Anaesth. 1990;37(1):77-93.

24. Kwek TK, Lew TW, Thoo FL. The role of preoperative cervical spine X-rays in rheumatoid arthritis. Anaesth Intensive Care. 1998;26(6):636-41.

25. Jin F, Chung F. Minimizing perioperative adverse events in the elderly. Br J Anaesth. 2001;87(4):608-24.

26. Lopez-Olivo MA, et al. Cervical spine radiographs in patients with rheumatoid arthritis undergoing anesthesia. JCR. 2012;18.2:61-6.

27. Cheng S-P, et al. Perioperative care of the elderly. International Journal of Gerontology. 2007;1.2:89-97.

28. Patel AY, Eagle KA, Vaishnava P. Cardiac risk of noncardiac surgery. J Am Coll Cardiol. 2015;66(19):2140-8.

29. Coblyn JS. Infections, drugs, and rheumatoid arthritis. What have we learned? J Rheumatol. 2008;35(3):375-6.

30. Loza E, Martinez-Lopez JA, Carmona L. A systematic review on the optimum management of the use of methotrexate in rheumatoid arthritis patients in the perioperative period to minimize perioperative morbidity and maintain disease control. Clin Exp Rheumatol. 2009;27(5):856-62.

31. Goodman SM, Paget S. Perioperative drug safety in patients with rheumatoid arthritis. Rheum Dis Clin N Am. 2012;38(4):747-59.

32. Goh L, Jewell T, Laversuch C, Samanta A. Should anti-TNF therapy be discontinued in rheumatoid arthritis patients undergoing elective orthopaedic surgery? A systematic review of the evidence. Rheumatol Int. 2012;32(1):5-13.

33. Krause ML, Matteson EL. Perioperative management of the patient with rheumatoid arthritis. World J Orthop. 2014;5(3):283-91. https://doi.org/10.5312/ wjo.v5.i3.283. 
34. Marathe PH, Gao HX, Close KL. American Diabetes Association standards of medical Care in Diabetes 2017. J Diabetes. 2017;9:320.

35. Falck-Ytter Y, Francis CW, Johanson NA, Curley C, Dahl OE, Schulman S, et al. Prevention of VTE in orthopedic surgery patients: antithrombotic therapy and prevention of thrombosis, 9th ed: American College of Chest Physicians Evidence-Based
Clinical Practice Guidelines. Chest. 2012;141(2 Suppl):e278S-325S.

36. Nieto JA, Espada NG, Merino RG, Gonzalez TC. Dabigatran, rivaroxaban and apixaban versus enoxaparin for thomboprophylaxis after total knee or hip arthroplasty: pool-analysis of phase III randomized clinical trials. Thromb Res. 2012 Aug;130(2):183-91.

Open Access This chapter is licensed under the terms of the Creative Commons Attribution 4.0 International License (http://creativecommons.org/licenses/by/4.0/), which permits use, sharing, adaptation, distribution and reproduction in any medium or format, as long as you give appropriate credit to the original author(s) and the source, provide a link to the Creative Commons license and indicate if changes were made.

The images or other third party material in this chapter are included in the chapter's Creative Commons license, unless indicated otherwise in a credit line to the material. If material is not included in the chapter's Creative Commons license and your intended use is not permitted by statutory regulation or exceeds the permitted use, you will need to obtain permission directly from the copyright holder. 